\title{
Virus as renal functional genetic tools
}

Abhishek Sharma ${ }^{1 *}$ and Sandhanakrishnan Cattavarayane ${ }^{2 *}$

Affiliation:

1 Biocenter Oulu, Faculty of Biochemistry and Molecular Medicine, University of Oulu, Finland.

2 Department of Veterinary Biosciences, Section of Pathology, Faculty of Veterinary Medicine, University of Helsinki, Helsinki.

*Corresponding Authors: Abhishek.Sharma@Oulu.fi \& Sandhana.Cattavarayane@Helsinki.fi

\begin{abstract}
Viral vectors enable efficient transfection of ectopic DNA into hard to transfect cells. Viral vectors are normally used to obtain permanent modification of target cells and tissues expect for the cases where integrase deficient viruses are used. Here we describe a method to stably transfect metanephric mesenchyme cells isolated from the murine embryonic kidney at day E11.5. Using this method, it is possible to transfect hard to transfect cells and successfully evade host tissue immune response. Due to these advantages, this method has become one for the most frequently used in generating stable cell line, manipulation of tissues and gene therapy.
\end{abstract}

Key words: Viral vectors, gene transfer, lentivirus, metanephric mesenchyme

\section{Introduction}

Viruses depend on their host cell machinery to complete its life cycle. Virus has to bind to the cell membrane of the host and transfer its genetic material into the cytoplasm. The viral genome is transcribed and replicated by the host cell machinery. Different types of viruses including retrovirus, adenovirus, adeno-associated virus and herpes simplex virus are used in the laboratory for applications like gene therapy (1).

Transfection of primary cell lines using methods like electroporation, nucleofection, lipofection and calcium phosphate transfection are inefficient and leads to cell death due to toxicity (2). Mouse embryonic kidney like any other primary tissue is hard to transfect with ectopic DNA. Efficient delivery of nucleic acid into these hard to transfect primary cells are achieved by means of viral vectors (3). Viral vectors comes with different advantages like high efficiency, immune-evasion, stable expression etc. 
Most commonly used $\gamma$-retroviral vectors have a limited host range and can infect only dividing cells (4). While lentiviruses, a sub class of retroviruses can infect both dividing and non-dividing cells $(\mathbf{5 , 6}$ ). But both $\gamma$-retroviruses and lentiviruses have a limitation in the size of gene the vector can host (7). Adenoviruses encounter an active immune response and hence are not suitable to use in tissue context (8).

\section{Materials}

Virus production and transduction takes place in a biosafety level 2 laboratory. The experiments were performed with the laboratory personnel wearing proper protection from gloves and lab coats. Viral particles produced were tested for replication incompetence. It was ensured that the transduce cells were devoid of any live virus before removing them outside of virus laboratory.

We used lentiviral vectors to transduce disassociated metanephric mesenchymal (MM) cells. Third generation lentiviral vectors were used to produce viruses containing green fluorescent protein (GFP) reporter genes. This system uses a four-plasmid system containing a packaging vector pLenti-GFP, and three helper plasmids pMD2.G, and pMDL g/p RRE and pRSV-Rev.

1. Human embryonic Kidney 293T (HEK-293T) cells.

2. Lipofectamine 2000 .

3. OptiMEM.

4. Growth Medium -DMEM, low glucose, $10 \%$ FCS, $0.1 \%$ penicillin/streptomycin.

5. $0.44 \mu \mathrm{m}$ Syringe filter.

\subsection{Dissociation of MM}

\subsubsection{Pancreatin-trypsin Solution and Collagenase}

1. Tyrode's Solution - $137 \mathrm{mM} \mathrm{NaCl}, 2.7 \mathrm{mM} \mathrm{KCl}, 1 \mathrm{mM} \mathrm{MgCl} 2,1.8 \mathrm{mM} \mathrm{CaCl}_{2}, 0.2 \mathrm{mM} \mathrm{Na}_{2} \mathrm{HPO}_{4}, 12$ $\mathrm{mM} \mathrm{NaHCO}$ and $5.5 \mathrm{mM}$ D-glucose.

2. Pancreatic-trypsin solution $-0.25 \mathrm{~g}$ of pancreatin from porcine pancreas (Sigma) and $0.17 \mathrm{~g} \mathrm{NaCl}$ was dissolved into $20 \mathrm{~mL}$ of sterile water on a magnetic stirrer for 3-4 hrs at room temperature. The solution was left on magnetic stirrer at $4^{\circ} \mathrm{C}$ overnight. The solution was centrifuged at $2700 \mathrm{~g}$ for 
$10 \mathrm{~min}$, the supernatant was aliquoted and stored at $-20^{\circ} \mathrm{C} .0 .45 \mathrm{~g}$ of Trypsin from porcine pancreas (Sigma) was dissolved in $2 \mathrm{~mL}$ of pancreatin solution (see above) and adjust the final volume to $20 \mathrm{~mL}$ with Tyrode's solution on ice. The $\mathrm{pH}$ of final solution was adjusted between 7.2-7.8. Pancreatin-trypsin solution was aliquoted and store at $-20^{\circ} \mathrm{C}$.

3. Earle's Balanced Salt Solution - $1.8 \mathrm{mM} \mathrm{CaCl}_{2}, 5.3 \mathrm{mM} \mathrm{KCl}, 0.8 \mathrm{mM} \mathrm{MgSO}_{4}, 117 \mathrm{mM} \mathrm{NaCl}, 26$ $\mathrm{mM} \mathrm{NaHCO} 3,1 \mathrm{mM} \mathrm{NaH}_{2} \mathrm{PO}_{4} \cdot \mathrm{H}_{2} \mathrm{O}$ and $5.6 \mathrm{mM}$ Glucose.

4. Collagenase III (Worthington) - Collagenase solution was prepared by diluting it in Earl's Balanced Salt Solution to obtain final concertation to $9400 \mathrm{U} / \mathrm{mL}$. The Collagenase solution was aliquoted and stored at $-20^{\circ} \mathrm{C}$.

\subsubsection{Preparation and Dissection of Embryos.}

1. Dumont \#5 forceps, fine tip.

2. Surgical Scissors.

3. 20-gauge hypodermic needles.

4. $5 \mathrm{~mL}$ Syringes.

5. Zoom stereomicroscope with transmitted light.

6. 1X Dulbecco's PBS without calcium and magnesium.

7. $10 \mathrm{~cm}$ glass and plastic petri dishes.

8. Pancreatin-trypsin solution (see Subheading 2.1.1).

9. Collagenase III $(9400 \mathrm{U} / \mathrm{mL})$.

10. DNase I (1U/mL) (Thermo Scientific).

11. Growth Medium: Dulbecco's modified Eagle's medium (DMEM) with GlutaMAX-I and $1,000 \mathrm{mg} / \mathrm{mL}$ glucose (Gibco), $10 \%$ FBS, $100 \mathrm{U} / \mathrm{mL}$ penicillin, $0.1 \mathrm{mg} / \mathrm{mL}$ streptomycin and $10 \mathrm{mM}$ HEPES.

\subsection{Transduction of MM}

1. Biosafety hood.

2. $4 \mathrm{mg} / \mathrm{mL}$ Polybrene (Sigma). 


\section{Methods}

All the methods described below were carried out inside a biological safety hood.

\subsection{Lentivirus production}

1. Nearly confluent (70-80\%) HEK 293 T cells were grown on Corning CellBind $10 \mathrm{~cm}$ cell culture dish.

2. One hour prior to transfection, the media in the cell culture dish was replaced with $5 \mathrm{ml}$ of fresh prewarmed growth medium.

3. To prepare the transfection mix, $80 \mu \mathrm{l}$ of Lipofectamine 2000 was added to $1 \mathrm{ml}$ of OptiMEM and incubated at room temperature for 5 minutes.

4. In another tube, $20 \mu \mathrm{g}$ of DNA was added in the following proportion. pLenti-GFP (target vector): pVSVG: pMDL g/p RRE: pRSV-Rev were used in 3:1:1:1 to $1 \mathrm{ml}$ of OptiMEM.

5. The DNA solution was mixed with OptiMEM containing Lipofectamine 2000 drop by drop with gentle tapping of the tube.

6. The above mixture was incubated at room temperature for 20 minutes.

7. The mixture was then added on top of the cells, swirled gently and cells were placed into humidified incubator $\left(+37^{\circ} \mathrm{C}, 5 \% \mathrm{CO} 2\right)($ See Note 3$)$.

8. 24 hours post transfection, medium containing the transfection mix was removed carefully and $5 \mathrm{ml}$ of fresh medium was added.

9. The medium supernatant containing the viral particles was collected every 12 hours for 3-4 days and stored at $+4^{\circ} \mathrm{C}$

10. The viral supernatants were pooled and centrifuged at $180 \mathrm{Xg}$ for 5 minutes and filtered through a $0.44 \mu \mathrm{m}$ filter.

11. The filtered viral supernatant was then concentrated by ultracentrifugation at $100000 \mathrm{Xg}$ for 2 hours.

12. The supernatant was discarded and the viral pellet resuspended in complete Dulbecco's phosphate buffered saline (1/100th of original volume) 
13. The resuspended virus is aliquoted and frozen at $-80^{\circ} \mathrm{C}$ until further use (See Note 3 ).

\subsection{Dissociation of MM}

1. Mouse embryo 11.5 days post coitum was obtained, at this time the ureteric bud will have invaded into MM.

2. After dissecting out the uterus, it was cut open in Dulbecco's PBS (without Calcium and Magnesium) using scissors and forceps.

3. The embryos were carefully transferred to a clean $10 \mathrm{~cm}$ plate filled with Dulbecco's PBS (without Calcium and Magnesium)

4. The embryos were removed from yolk sac under stereomicroscope using needles attached to syringes.

5. The embryo was cut into half between cranial and the hind limbs and the tail was shortened.

6. The caudal part of the embryo was placed with the ventrally side towards the bottom and the hind limbs were excised.

7. The remaining caudal embryo was placed on its side and the dorsal part was cut off just ventral to the spinal cord

8. Any excess tissue around the exposed metanephroi was removed.

9. Pancreatin-trypsin solution was melted in a low binding $1.5 \mathrm{~mL}$ Eppendorf tube.

10. In a $6 \mathrm{~cm}$ glass petri dish warm culture medium was added.

11. The collected metanephroi was added to the pancreatin-trypsin solution for 30 secs and immediately transferred to the petri dish containing warm culture medium.

12. Any remnants of the Wolffian duct was removed. By scratching the mesenchyme gently with one needle the ureteric bud was exposed and pulled out while holding the tissue in place with another needle.

13. The collected MM was added to dissociation solution prepared by adding $40 \mu \mathrm{L}$ of collagenase and $10 \mu \mathrm{L}$ of DNase to $280 \mu \mathrm{L}$ of physiological buffer.

14. The cell suspension was incubated at $37^{\circ} \mathrm{C}$ for 20 mins in an atmosphere of $5 \% \mathrm{CO}_{2}$.

15. The MM is dissociated into a single cell suspension by pipetting carefully under a stereomicroscope. 
16. $600 \mu \mathrm{L}$ of warm culture medium was added and the cells were pelleted by centrifuging at $1380 \mathrm{~g}$ for 5 mins at room temperature.

17. The supernatant was discarded and warm culture medium was added along with $50 \mathrm{ng} / \mathrm{ml}$ of BMP7 and 100ng/ml FGF2 and the cells were kept on ice.

\subsection{Lentivirus transduction}

1. Under the biosafety hood, polybrene was added to the metanephric mesenchyme cells to make a final concentration of $4 \mu \mathrm{g} / \mathrm{mL}$.

2. The cells were divided into two low bind $1.5 \mathrm{~mL}$ Eppendorf tubes carefully marking them.

3. In a fresh tube warm culture medium containing BMP7 and FGF2, was added followed by virus solution. The final volume was adjusted so that the growth factor concentration remains $50 \mathrm{ng} / \mathrm{ml}$ and 100ng/ml for BMP7 and FGF2, respectively.

4. The transfection mix was incubated at $37^{\circ} \mathrm{C}$ in $5 \% \mathrm{CO}_{2}$ for $2 \mathrm{hrs}$.

5. Subsequently, the cells were pelleted at $1380 \mathrm{~g}$ for $5 \mathrm{mins}$ at room temperature.

6. The supernatant was removed and discarded. Warm culture medium containing BIO (GSK-3 inhibitor) was added.

7. The cells were pelleted at $1380 \mathrm{~g}$ for 20 mins and the pellet was incubated at $37^{\circ} \mathrm{C}$ in $5 \% \mathrm{CO}_{2}$.

8. After $16 \mathrm{hrs}$ of induction with BIO (GSK-3 inhibitor) the pellet was carefully removed using a glass pipette and carefully placed into Trowell Culture.

\section{Notes}

1. HEK 293T cells detach very easily post transfection. Care should be taken while collecting virus and adding new medium. Medium should be gently added dropwise to the sides of the cell culture dish. Care should be taken while removing and putting back the dishes from and into the incubator. The number of attached cells will directly affect the final viral titer. 
2. The pellet can be immediately resuspended or can be placed at $+4^{\circ} \mathrm{C}$ overnight to improve the efficiency of resuspension. Overnight protocol helps in better resuspension and thereby improve the efficiency of infection.

3. Once the virus is concentrated and resuspended, it should be aliquoted and frozen. Lentiviral particles pseudotyped with VSVG are quite strong and can withstand multiple freeze thaw cycles. But the efficiency of infection decreases with every round of freeze thaw. It is better to have aliquots of desired size, which can be completely utilized for infection upon thawing.

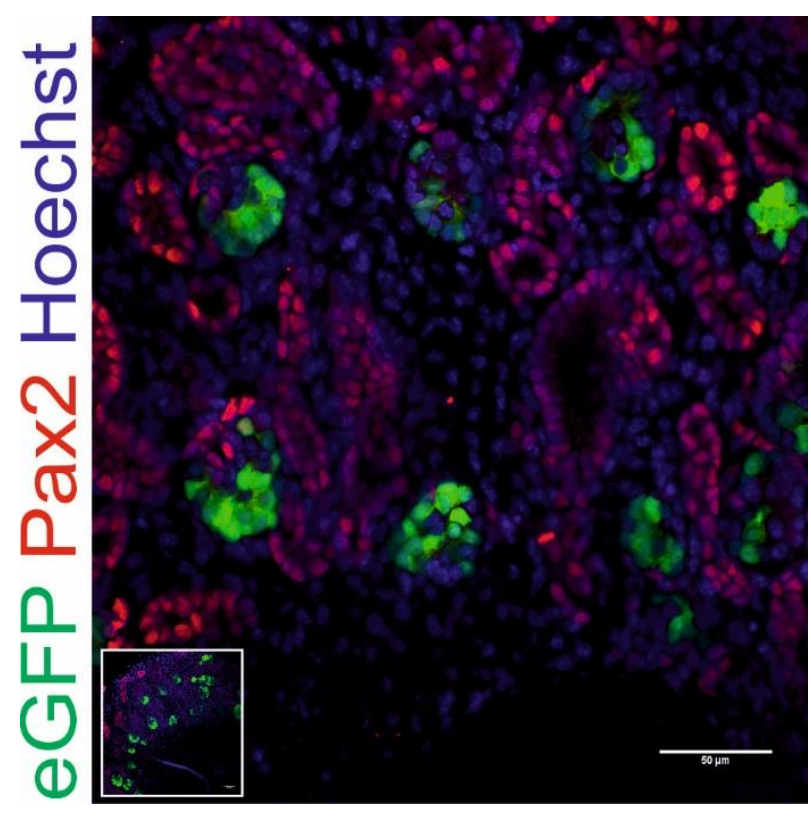

Figure 1. Virus mediated knock-down of Lim-1 (Lim1 shRNA-eGFP) in dissociated metanephric mesenchyme. Epithelial structures are stained with Pax2. (Junttila et al. unpublished data)

\section{References}

1. Bouard D, Alazard-Dany D, Cosset FL (2009) Viral vectors: from virology to transgene expression. Br J Pharmacol 157(2):153-165. 10.1038/bjp.2008.349 [doi]

2. Maurisse R, De Semir D, Emamekhoo H et al (2010) Comparative transfection of DNA into primary and transformed mammalian cells from different lineages. BMC Biotechnol 10:9-6750-10-9. 10.1186/14726750-10-9 [doi]

3. Junttila S, Saarela U, Halt K et al (2015) Functional genetic targeting of embryonic kidney progenitor cells ex vivo. J Am Soc Nephrol 26(5):1126-1137. 10.1681/ASN.2013060584 [doi]

4. Spiegel M, Bitzer M, Schenk A et al (1998) Pseudotype formation of Moloney murine leukemia virus with Sendai virus glycoprotein F. J Virol 72(6):5296-5302

5. Naldini L, Blomer U, Gallay P et al (1996) In vivo gene delivery and stable transduction of nondividing cells by a lentiviral vector. Science 272(5259):263-267 
6. Yamashita M, Emerman M (2006) Retroviral infection of non-dividing cells: old and new perspectives. Virology 344(1):88-93. S0042-6822(05)00585-4 [pii]

7. Yi Y, Noh MJ, Lee KH (2011) Current advances in retroviral gene therapy. Curr Gene Ther 11(3):218228. ABS- 71 [pii]

8. Muruve DA (2004) The innate immune response to adenovirus vectors. Hum Gene Ther 15(12):11571166. 10.1089/hum.2004.15.1157 [doi] 